\title{
A WEB APPLICATION TO OPTIMIZATION OF TRANSPORT IN MILITARY OPERATIONS
}

Aguilar, Hardy; González, Patricio; Molina, Matías; Quila, Daniela; Gatica, Gustavo; Coronado-Hernández, J. R.; Baron-Villamizar, Javier; Silva, Jesús

\begin{abstract}
Transport is an operation necessary to carry out any logistical mission, especially in times of war, peace or natural disasters. The distribution of the necessary demanded resources is done from a military unit, to the different locations or military bases. However, operational efficiency depends on the planners. In more than $60 \%$ of trips, shipping and return isn't efficient, even between the same units. The cause is the nonconsolidation of trips and the lack of return load, coming from perimeter units. Planning is done without consolidating trips and in many cases on demand. It's presented a web application, a parametric framework to any geographical area, given the integration with applications such as Google Maps ${ }^{\circledR}$. Computational times are reasonable, given a to hardiness to the problem. The software architecture is scalable and extensible, complying with software quality practices present in ISO 25000 .
\end{abstract}

\section{Keywords}

Military logistics, Vehicle routing, Web application 